\title{
En torno a la libertad humana
}

\section{Prenotandos.}

1. ${ }^{\circ}$ La existencia tanto de la voluntad humana como del libre albedrío es una verdad inconcusa para el filósofo y un dogma de fe para el teólogo.

2. $\quad$ En cuanto a su naturaleza, la voluntad humana y el libre albedrío son físicamente una y misma potencia espiritual ordenada naturalmente al bien, ya sea éste el del fin ya el de los medios: en cuanto ordenada al bien del fin, es voluntad; en cuanto ordenada al bien de los medios, es libre albedrío o libertad. $\mathrm{Y}$ tan es así que la voluntad - bajo ambas formalidades- es "appetitus boni", que el primer acto o movimiento de la voluntad es el amor del bien.

"Primus, ait Angelicus, motus voluntatis et cujuslibet appetitivae virtutis est amor. Cum enim actus voluntatis et cujuslibet appetitivae virtutis tendat in bonum et malum, sicut in propria objecta; bonum autem principalius et per se sit objectum voluntatis et appetitus; malum autem secundario et per aliud, inquantum scilicet opponitur bono: oportet naturaliter esse priores actus voluntatis et appetitus qui respiciunt bonum, his qui respiciunt malum; ut gaudium quam tristitiam, et amorem quam odium. Semper enim quod est per se, prius est eo quod est per aliud. Rursus, quod est communius naturaliter est prius. Unde et intellectusı per prius habet ordinem ad verum commune quam ad particularia quaedam vera. Sunt autem quidam actus voluntatis et appetitus respicientes bonum sub aliqua speciali conditione: sicut gaudium et delectatio est de bono praesenti et habito; desiderium et spes de bono nondum adepto. Amor autem respicit bonum in communi, sive sit habitum, sive non habitum. Unde amor est primus actus voluntatis et appetitus: Et propter hoc omnes alii motus appetitivi praesupponunt amorem, quasi primam radicem. Nullus enim desiderat aliquid nisi bonum amatum; neque aliquis gaudet nisi de bono amato. Odium etiam non esit nisi de eo quod contrariatur rei amatae. Et similiter tristitiam, et caetera hujusmodi, manifestum est in amorem referri sicut in primum principium. Unde in quocumque est voluntas vel appetitus, oportet esse amorem. Remoto enim primo, removentur alia" 1.

El amor, pues, es el "primus motus voluntatis" y, en consecuencia, "quasi prima radix" de todos los demás movimientos apetitivos. Con razón y sobrada

\footnotetext{
1 S. Th. I, XX, 1 .
} 
experiencia pudo decir San Agustín: "PONDUS MEUM, AMOR MEUS; EO FEROR QUOCUMQUE FEROR" 2 .

3. La voluntad no puede querer ni el mal sub ratione mali, ni el pecado sub ratione peccati, toda vez que uno y otro se oponen al bien y son por naturaleza "privatio boni". De aquí la razón de ser del odio y del amor.

"In appetitu animali seu intellectivo amor est consonantia quaedam appetitus ad id quod apprehenditur ut conveniens; odium vero est disonantia quaedam appetitus ad id quod apprehenditur ut nocivum. Sicut autem omne conveniens, inquantum hujusmodi, habet rationem boni; ita omne repugnans inquantum hujusmodi, habet rationem mali; et ideo sicut bonum est objectum amoris, ita malum est objectum odii" 3 .

Y hasta tal punto queda excluído del ámbito del amor (sino es per accidens) el mal en sí -físico o moral-, que explicando el Angélico la definición del bien dada por Aristóteles: "Bonum est quod omnia appetunt", escribe resueltamente :

"Cum dicitur, "Bonum est quod omnia appetunt", non sic intelligitur, quasi unumquodque bonum ab omnibus: appetatur; sed quia quidquid appetitur rationem boni habet" 4.

Y si de hecho queremos también -como sabemos por triste experiencialo malo, sin embargo, siempre será verdad que "Voluntas vult naturaliter bonum... Et propter hoc, quidquid vult, vult sub ratione boni" 5 .

4. ${ }^{\circ}$ Soslayando otras divisiones del bien, éste puede ser : deleitable -útilhonesto; según que su apetibilidad radique respectivamente en la mera delectación, o en la simple razón de medio, o en su propia y nuda bondad.

"Dicuntur enim illa proprie delectabilia, quae nullam habent aliam rationem appetibilitatis, nisi delectationem; cum aliquando sint et noxia et inhonesta. Utilia vero dicuntur, quae non habent in se unde desiderentur, sed desiderantur solum, ut sunt ducentia in alterum; sicut sumptio medicinae amarae. Honesta vero dicuntur quae in seipsis habent unde desiderentur" 6.

\section{CONCEPTO DE LIBERTAD.}

Comúnmente se funda la libertad humana en la intrínseca o natural indeterminación de la voluntad frente al bien inadecuado a su apetito del bien sumo;

2 Conf. XIII,9, 10; M. L. 32, 849.

3 S. Thomas: S. Th. 1, 2, XXIX, 1 .

4 S. Th. I, VI, 2, ad 2.um.

5 De Veritate, XXII, 6, ad 5.

6 S. Th. I, V, 6, ad 2.um. 
y se define, en el fondo, por la generalidad de los autores: "Activa indifferentia ab intrinseco, vi cujus voluintas potestatem dominativam super actum suum babet, ita ut, positis omnibus requisitis ad agendum, possit agere et non agere" 7 . De aquí la usual distinción en libertad:

a) de contradicción: indiferencia para querer o no querer;

b) de especificación: indiferencia para elegir unum prae alio,

c) de contrariedad: indiferencia para optar por el bien o por el mal.

Pero, salvo mi máximo respeto — por exigirlo la prüdencia más elementala los autores de esta doctrina más o menos generalizada en los "Manuales", pregunto: ¿es correcta la precedente definición de la libertad humana?

A mí se me antoja que no. Razón: porque el libre albedrío no puede quedar o mantenerse indiferente e inactivo en presencia de su objeto específico y adecuado, que es el bien en razón de medio, cuando la voluntad quiere lograr otro bien, que es, en definitiva, el bien del fin. Pues querer de hecho el fin y no querer de hecho los medios - sean cuales fueren- sería querer y no querer al mismo tiempo el fin, cosa a todas luces contradictoria. Nada, por tanto, de indiferencia o indeterminación intrínseca en la libertad de albedrío ${ }^{8}$ respecto de los medios - sean, repito, cuales fueren - cuando la voluntad quiere realmente bic et nunc lograr un determinado fin, blanco de su apetito.

Digo más: puesto a elegir de hecho entre varios medios desigualmente aptos, el libre albedrío elegitá ciertamente el conceptuado - lo sea o no en sí- como mejor. Razón general : Forque de otro modo el "appetitus intellectivus" dejaría de ser "intellectivus appetitus". De aquí que repute óptima - salvo mejor juicio- la definición auténticamente tomista de la libertad humana: "VIS ELECTIVA MEDIORÜM, SERVATO ORDINE FINIS" 9 .

Ahora bien, partiendo de que la libertad o libre albedrío es "vis electiva mediorum servato ordine finis", el medio que elige en todo caso la voluntad humana cuando de hecho quiere - no veleidosa sino eficazmente- un determinado fin, es, repito, el conceptuado por la inteligencia - lo sea o no en sícomo mejor.

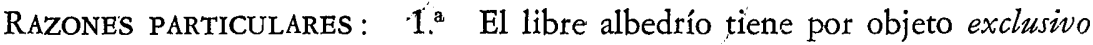
el bien del medio en cuanto medio; así como la voluntad el bien del fin bajo la razón exclusiva de fin. Pero de varios medios que la inteligencia reputa disponibles, buenos y con distinto grado de bondad, los menos buenos son malos

7 J. GREDT, Ellementa pihilosophiae aristotelico-thomisticae, t. I, th. 58.

8 La supuesta indiferencia del libre albedrío sería cuando más un estado de la potencia o libre albedrío, no el libre albedrío o la potencia en sí: indiferencia-activa me parece una contradictio in terminis, supuesto el appetitus finis hic et nunc y el posible uso del medio adecuado.

9 Cfr. S. Th. I, 83, 4; I. 62, 8, ad 3. 
respecto del mejor, ya que en los menos buenos se da una privación de bien si se comparan con el mejor, y "malum est privatio boni". Luego de varios medios que la inteligencia reputa disponibles, buenos y con distinto grado de bondad, el libre albedrío tiene por objeto exclusivo el mejor; o, lo que es igual, elegirá de entre ellos el aprehendido por la inteligencia como mejor.

2. La libertad es "vis electiva mediorum servato ordine finis". Ahora bien, el orden del fin se conserva tanto más incólume cuanto mejor sea el medio. Luego la libertad es "vis electiva" del mejor medio.

$3 .^{a}$ Lo que repugna al orden, repugna al principio del orden, que es la recta razón. Ahora bien, elegir un medio menos bueno cuando hay otro mejor, respecto del fin debido, repugna al orden (= "recta ratio rerum ad finem"). Luego elegir un medio menos bueno cuando hay otro mejor, respecto del fin debido, repugna al principio del orden que es la recta razón. O dicho con otras palabras: La recta razón, ordenadora de los medios, antepone el mejor al menos bueno cuando se trata de disponerlos para el logro del fin debido. Ahora bien, el libre albedrío es "apetito intelectivo". Luego el libre albedrío antepone (= elige) el medio mejor al menos bueno para el logro del fin debido ${ }^{10}$.

$4 .^{a} \quad$ La libertad de albedrío radica:

-En la tendencia natural de la voluntad al bien universal.

-En la contingencia y finitud de los bienes creados.

-En el juicio ponderado de la recta razón.

De donde se infiere, que la libertad de albedrío ha de estar a tono y de todo en todo concorde con el juicio de la recta razón. Pero el juicio de la recta razón se termina en lo juzgado como más verdadero ( = cierto o cuando menos más probable, a falta de certeza). Luego la libertad de albedrío se termina en lo rectamente juzgado como mejor - bonum et verum convertuntur-, o, lo que es igual, elige de entre varios medios, desigualmente buenos, el mejor.

5. La voluntad humana es tanto más libre - expedita - en orden a lograr un fin, y, si se quiere, el fin de los fines, que es el Bien Sumo, cuanto más adecuados sean los medios elegidos por ella para lograrle. Ahora bien, los medios más adecuados para lograr un fin $y$, si se quiere, el fin de los fines, oue es el Bien Sumo, son evidentemente los aprehendidos por la recta razón como mejores. Luego la voluntad humana es tanto más libre en orden a lograr un fin y, si se quiere, el fin de los fines, aue es el Bien Sumo, cuanto mejores sean los medios elegidos por ella para lograrle. De aquí que:

6. ${ }^{2}$ Los santos son tanto más libres cuanto más certera es la elección de los medios encaminados a Dios, primera causa final. Pero la elección más certera de tales medios es la de los mejores. Luego los santos son tanto más libres cuanto 
más certera es la elección de los medios mejores, encaminados a Dios, primera causa final. $\mathrm{Y}$ a fortiori valdría este argumento si se le aplica a los viadores confirmados en gracia, que no por ello pierden, como es sabido, la libertad ${ }^{11}$.

Por último: en la S. Th., 1, 2, XIII, 6, obj. 3 -en contra de la libertad humana- se pone, con carácter de premisa-principio, esta subsunta: "Omnis electio est de omni eo quod videtur aliquo modo melius". Ahora bien, Santo Tomás, lejos de rechazarla como falsa, la da, sin duda, por verdadera - en la respuestadiciendo:

"Nihil prohibet, si aliqua duo aequalia proponantur secundum unam considerationem, quin circa alterum consideretur aliqua conditio per quam emineat, et magis flectatur voluntas in ipsum quam in aliud".

"Emineat" aquí = melius esse. Luego...

EN CONCLUSIÓN :

Abstracción hecha de toda concomitancia o de toda otra mira desorbitada, aseveramos que la voluntad - bajo su doble aspecto de apetito natural y de apetito intelectivo- quiere per se el bien y elige per se de entre los medios en sí buenos el mejor.

Puede ocurrir, sin embargo, que "per accidens" la voluntad quiera el mal intentando un fin malo o eligiendo un medio malo; pero entonces intenta o elige el mal bajo la apariencia de bien; por eso dije que abstracción hecha de toda concomitancia o de toda otra mira desorbitada, e. d., objetivamente falsa.

Y cabe también - lo que es frecuente- que la voluntad quiera y elija "per accidens" el mal que acompaña a un bien, caso que éste sea conceptuado mayor o mejor que el bien de que priva el mal.

"Cum ratio boni, ait Angelicus, sit ratio appetibilis, ut supra dictum est, malum autem opponatur bono; impossibile est quod aliquod malum, inquantum hujusmodi, appetatur, neque appetitu naturali, neque animali, neque intellectuali, qui est, yoluntas. Sed aliquod malum appetitur per accidiens, inquantum consequitur adl aliquodl bonum. Et hoc apparet in quolibet appetitu. Non enim ágens naturale intendit privationem nec corruptionem; sed formam, cui conjungitur privatio alterius formae; et generationem unius, quae est corruptio alterius. Leo etiam, occidens cervum, intendit cibum, cui conjungitur occisio animalis. Similiter fornicator intendit delectationem, cui conjungitur deformitas culpae. Malum autem quod conjungitur alicui bono, est privatio alterius boni. NUNQUAM IGITUR APPETERETUR MALUM, NEC PER ACCIDENS, NISI BONUUM CUI CONJUNGITUR MA-

11. Cfr. S. Th. I, 62, 8, ad 3 . 
LUM, MAGIS APPETERETUR, QUAM BONUM QUOD PRIVATUR PER MALUM" (S. Th. I, XIX, 9) 12 .

Objetará alguien: si esto es así ¿cómo se explica el pecado? Porque siendo éste un "acto humano malo" ${ }^{13}$, y acto humano "sit actus qui est a ratione procedens voluntarius" 14 ; forzoso sería concluir, que el pecado es una volición especificada por un objeto malo, en cuanto término de la volición. De donde, una de dos: o no es posible el pecado, o es falso que la voluntad no quiera libre y directamente el mal. Si lo primero, reclama en contra la fe. Si lo segundo, hay que negar la libertad de albedrío en cuanto "vis electiva mediorum servato ordine finis". Pero no se puede admitir lo que va contra la fe. Luego hay que negar la libertad de albedrío, en cuanto "vis electiva mediorum servato ordine finis".

\section{EL PECADO Y LA LIBERTAD.}

El pecado, moralmente hablando, "provenit ex eo quod voluntas deficit debito fine, per hoc quod in finem indebitum tendit" (De Malo, III, 1), o, lo que es igual, "causatur a libero arbitrio secundum quod deficit a Deo" (1. c. ad 4). Y, como Dios es el Bien Sumo, de aquí que pueda definirse el pecado: "aversio voluntatis a summo bono". (l. c.). Y como el bien sumo = al fin último, podemos decir también que el pecado "consistit in aversione voluntatis creatae ab ultimo fine" (1. c.) y es, en consecuencia, "actus privatus debito ordine". (De Malo, II, 1, ad 4.)

Pero hemos dicho que la libertad de albedrío es "vis electiva mediorum servato ordine finis". Luego el que el libre albedrío "eligat aliquid, quod est peccare, divertendo ab ordine finis, hoc pertinet ad defectum libertatis" ${ }^{15}$.

Podrá inferirse de aquí que el libre albedrío deja de ser libre albedrío cuando peca -y por tanto que el pecado no le es imputable al hombre-, o que si peca sin dejar de ser libre albedrío elegirá el mal sub ratione mali? De ningún modo. Cierto que el pecado (= actus humanus malus) es un mal; y que "velle malum nec est libertas nec pars libertatis, quamvis sit quoddam libertatis

12 He aquí otra prueba de que la voluntad quiere siempre de dos bienes desiguales el mayor, y, por consiguiente, elige siempre de dos o más medios buenos el mejor. De otro modo sería fútil —absit! — la argumentación del Angélico:

"NUNQUAM IGITUR... PER MALUM. Nullum autem bonum Deus magis vult quam suam bonitatem... Unde malum culpae, quod privat ordinem ad bonum divinum, Deus nullo modo: vult".

13. S. Th. 1, 2, q. 61, a. 6.

De Malo, II, 6 .

S. Th. I, 62,8 , ad 3 . 
signum" 16. Cierto también, como dijimos antes, que: "Cum ratio boni sit ratio appetibilis, malum autem opponatur bono; impossibile est quod aliquod malum, inquantum bujusmodi, appetatur" 17 .

Pero no es menos cierto:

1. Que la voluntad es una potencia que se define: "appetitus boni", y que "est de ratione potentiae ut tendat in suum objectum" 18 , de donde se sigue que "quidquid vult, vult sub ratione boni" 19 .

2. Que el libre albedrío es "appetitus intellectivus", y, por tanto, que no se da ni puede darse elección sin juicio; por eso se define el acto humano: "Actus qui est a ratione procedens voluntarius" 20.

3. Que la voluntad natural y la voluntad deliberada ("voluntas ut natura et voluntas ut voluntas") dependen esencialmente de la razón en cuanto a sus voliciones o elecciones; de aquí el axioma: nihil volitum quin praecognitum.

4. ${ }^{\circ}$ Que la razón humana es falible per accidens en sus juicios; de donde se infiere, que puede a veces juzgar bueno lo que por sí o sus circunstancias es malo, y, en consecuencia, le presente a la voluntad el mal bajo apariencia de bien, es decir, un bien falaz, ficticio, aparentemente bueno, siendo, por el contrario, realmente malo: de aquí que el libre albedrío elija a veces un medio en sí malo, y la voluntad quiera a veces también un fin en sí malo; pero evidentemente la elección no recae ni puede recaer entonces sobre el medio malo en cuanto malo; ni la volición en el fin malo en cuanto malo; sino en uno y otro, respectivamente, sub specie boni.

Secuela, pues, lógica y general: lejos de ser incompatibles - como se objetaba- la libertad y el pecado, el pecado es de todo en todo imposible sin la libertad: de aquí su justa imputabilidad.

Fr. Juventino Macho, O. S. A.

16. De Veritate, XXII, 6.

S. Th. I, XIX, 9.

S. Th. I, XIX, 3.

De Veritate, 22,6 , ad 5 .

De Malo, II, 6. 